\title{
Humedales en la franja de médanos costeros entre Monte Hermoso y Pehuen Có, provincia de Buenos Aires, Argentina. Tipificación hidrológica.
}

\author{
Andrés Gabriel Ruffo ${ }^{(1)}$, René Albouy ${ }^{(2)}$, Nerea Bastianelli(2) y Jorge Carrica ${ }^{(2)}$ \\ (1) Universidad Nacional del Sur, Departamento de Geología - CONICET. San Juan 670, (8000) Bahía Blanca, Argentina. \\ E-mail: andres.ruffo@uns.edu.ar \\ (2) Universidad Nacional del Sur, Departamento de Geología - CGAMA. San Juan 670, (8000) Bahía Blanca, Argentina. \\ albouy@uns.edu.ar; nerea.bastianelli@uns.edu.ar; jcarrica@uns.edu.ar.
}

\begin{abstract}
RESUMEN
La zonificación hidrogeológica de la provincia de Buenos Aires reconoce la denominada Costa Atlántica Bonaerense. El rasgo distintivo de ésta es la presencia casi continua de una cadena de médanos o dunas, que se extiende desde la Bahía de Samborombón hasta Bahía Blanca. Estas acumulaciones de arena favorecen la rápida infiltración del agua de lluvia y el almacenamiento de agua dulce, que es la única fuente de aprovisionamiento en las localidades costeras.

Este trabajo, que se enmarca en un proyecto de investigación más amplio, tiene por objetivo reconocer y tipificar los sectores de humedales que se identifican en la franja medanosa que se extiende entre los balnearios Monte Hermoso y Pehuen Có. Para ello se aplica una conocida metodología de caracterización hidrológica, que tiene en cuenta factores tales como: origen del agua, modo de vaciado, hidroperíodo, tasa de renovación y composición hidroquímica. El estudio se basa en información de campo y laboratorio, trabajos científicos antecedentes e interpretación de imágenes satelitales. La presencia y funcionamiento hidrológico de estos humedales está vinculada a la hidrodinámica del acuífero y, en particular, a las zonas de descarga. El agua en la superficie, en las zonas intermédanos, constituye una singularidad de estos espacios naturales. Esta contribución permite conocer algunos humedales en la franja medanosa costera, localizarlos y definir cuál es su nivel de integridad. Es necesario investigar la variabilidad espacial y evolución hidroquímica temporal. Se advierte sobre la importancia ambiental de estos entornos y su necesidad de correcta gestión y conservación.
\end{abstract}

Palabras Clave: Costa, Duna, Humedales, Tipificación.

\section{Wetlands in the coastal dunes between Monte Hermoso and Pehuen Có, Buenos Aires province, Argentina. Hydrological typification}

\begin{abstract}
This research, which is part of a larger research project, aims to recognize and typify the wetland sectors which are identified in the dunes line between the Monte Hermoso city and Pehuen Có village, in the southwest coast of Buenos Aires province, Argentina. A well-known hydrological characterization methodology is applied, which takes into account factors such as water origin, emptying mode, hydroperiod, renewal rate, and hydrochemical composition. The study is based on field and laboratory information, scientific background works and interpretation of satellite images. The presence and hydrological functioning of these wetlands are essentially linked to the aquifer's hydrodynamics and, in particular, to the discharge zones. The presence of superficial water between the dunes constitutes a singularity of these natural spaces. This contribution allows knowing some wetlands in the coastal dunes, locate them and define their level of integrity. It is necessary to investigate the spatial variability and temporal hydrochemical evolution. It warns about the environmental importance of these environments and their need for proper management and conservation.
\end{abstract}

Keywords: Classification, Coast, Coastal Dunes, Wetlands. 


\section{Introducción}

La zonificación hidrogeológica de la provincia de Buenos Aires, basada en la identificación de ambientes con características o comportamientos distintivos en relación al agua subterránea, reconoce la denominada Costa Atlántica Bonaerense (Auge, 2004; González, 2005). El rasgo distintivo de ésta es la presencia casi continua de una cadena de médanos o dunas, que se extiende desde la Bahía de Samborombón hasta Bahía Blanca. Estas acumulaciones de arena tienen gran importancia hidrogeológica ya que favorecen la rápida infiltración del agua de lluvia y el almacenamiento de agua dulce. Dicho recurso subterráneo es la única fuente de aprovisionamiento, para todo uso en las localidades balnearias costeras de Monte Hermoso y Pehuen Có, dentro del área de estudio. La primera de ellas tiene una población estable de 6351 habitantes y la segunda de 681 (INDEC, 2010). En ambos casos, el servicio de agua potable es municipal de gestión directa (Di Martino et al., 2016).

De acuerdo a las Regiones de humedales de la Argentina (Blanco et al., 2017), esta franja de dunas costeras se incluye en la Región de humedales costeros con "Predominio de ambientes terrestres con humedales de pequeña extensión". El modelo conceptual hidrológico de estos humedales está relacionado al agua subterránea y por tanto es útil conocer cómo los acuíferos condicionan su presencia y funcionamiento. Una singularidad de este ambiente medanoso lo constituye la presencia de agua en superficie, vinculada a la descarga de agua subterránea en los sectores intermédanos o zonas topográficamente deprimidas.

Este aporte tiene como objetivo presentar la primera caracterización o tipificación de estos humedales, de significación local y en los que la aportación de agua desde los acuíferos cumple un rol fundamental. Conocer esta vinculación es básico para plantear una gestión del agua que tenga en cuenta la conservación de estos ambientes naturales (Manzano, 2015). No obstante, hoy día no se advierten conflictos ambientales derivados de la explotación del agua subterránea en el área del estudio. La extracción de agua dulce más intensiva se centra en los dos núcleos urbanos ya citados, principalmente Monte Hermoso.

\section{Metodología}

El actual estado del conocimiento de la hidrología de los humedales ha permitido desarrollar modelos conceptuales de funcionamiento y métodos de clasificación. En este aporte se sigue una metodología de clasificación de humedales basada en características hidrogeomorfológicas, que tiene como base una tipificación que considera los factores hidrológicos dominantes como son el origen del agua, el modo de vaciado, el hidroperíodo, la tasa de renovación y elementos complementarios como hidrodinámica e hidroquímica (Manzano et al., 2002). El estudio se basa en información relevada en campañas de campo realizadas en los meses de invierno del año 2018. Se relevaron datos de profundidad del nivel freático con sonda piezométricas OTT y determinaciones hidroquímicas in situ ( $\mathrm{pH}, \mathrm{C}$.E y temperatura) del agua del acuífero y de las lagunas mediante un medidor multiparamétrico portátil Lutron WA-2015. El procesamiento de los datos se realizó en gabinete, con el apoyo de trabajos científicos antecedentes, cartas topográficas del Instituto Geográfico Militar a escala 1:50.000, interpretación y análisis morfométrico de los cuerpos de agua a partir de imágenes satelitales y elaboración-planteo de modelos hidrológicos hipotéticos.

\section{Área de estudio}

El área de estudio (Figura 1) se ubica en la costa atlántica suroccidental de la provincia de Buenos Aires, Argentina. Se extiende desde el balneario Monte Hermoso a los $38^{\circ} 59^{\prime} 33^{\prime \prime}$ (LS) y $61^{\circ} 15^{\prime} 55^{\prime \prime}$ (LO) hasta los $38^{\circ} 59^{\prime} 33^{\prime \prime}$ (LS) y $61^{\circ} 15^{\prime} 55^{\prime \prime}$ (LO) por el oeste. Incluye a la localidad turística de Pehuen Có. Limita al noreste con el partido de Coronel Dorrego y abarca parte de los partidos de Monte Hermoso y Coronel Rosales, en el sur bonaerense cubriendo una superficie aproximada de $280 \mathrm{~km}^{2}$.

\section{Medio físico}

El área del estudio tiene un clima de tipo templado, propio de las latitudes medias. De acuerdo al Servicio Meteorológico Nacional, para Bahía Blanca (estación meteorológica ubicada a 61,5 km de Pehuen Có y a unos $78 \mathrm{~km}$ de Monte Hermoso) y para el período 1981-2010 se indica un valor medio de precipitación de $651,4 \mathrm{~mm} / \mathrm{a}$ y una temperatura media anual de 15,5 ${ }^{\circ} \mathrm{C}$. El mes más frío es julio $\left(8^{\circ} \mathrm{C}\right)$ y el más caluroso enero $\left(23,5^{\circ} \mathrm{C}\right)$. La distribución interanual de las Iluvias indica que se producen principalmente a inicios del otoño y comienzos de la primavera, en tanto que el invierno y el verano son las estaciones secas. La evapotranspiración potencial calculada por el método de Thornthwaite (1948) arroja un valor de 779,88 $\mathrm{mm} / \mathrm{a}$, lo cual indica un predominio de déficit hídrico.

El sector se caracteriza por altitudes que oscilan entre los 0 y $40 \mathrm{msnm}$ y presenta una importante cadena de médanos o dunas costeras, móviles o activas, semifijas por vegetación y fijas. La faja de dunas se desarrolla por detrás de las zonas de playa. Las dunas tienen forma y altura variables y el ancho frecuente de los cordones es de unos 3 hasta $5 \mathrm{~km}$ desde la costa. Se trata de un relicto arenoso generado por la acción del mar sobre los "sedimentos pampeanos" y expuestos posteriormente a la acción del viento (Auge, 2004). La presencia de agua en la superficie, en las zonas interdunales, constituye una característica de estos ambientes.

Hacia el continente y en el límite entre la faja arenosa y la llanura, se identifican también dos cuerpos de agua permanentes, las lagunas Sauce Grande (hacia 


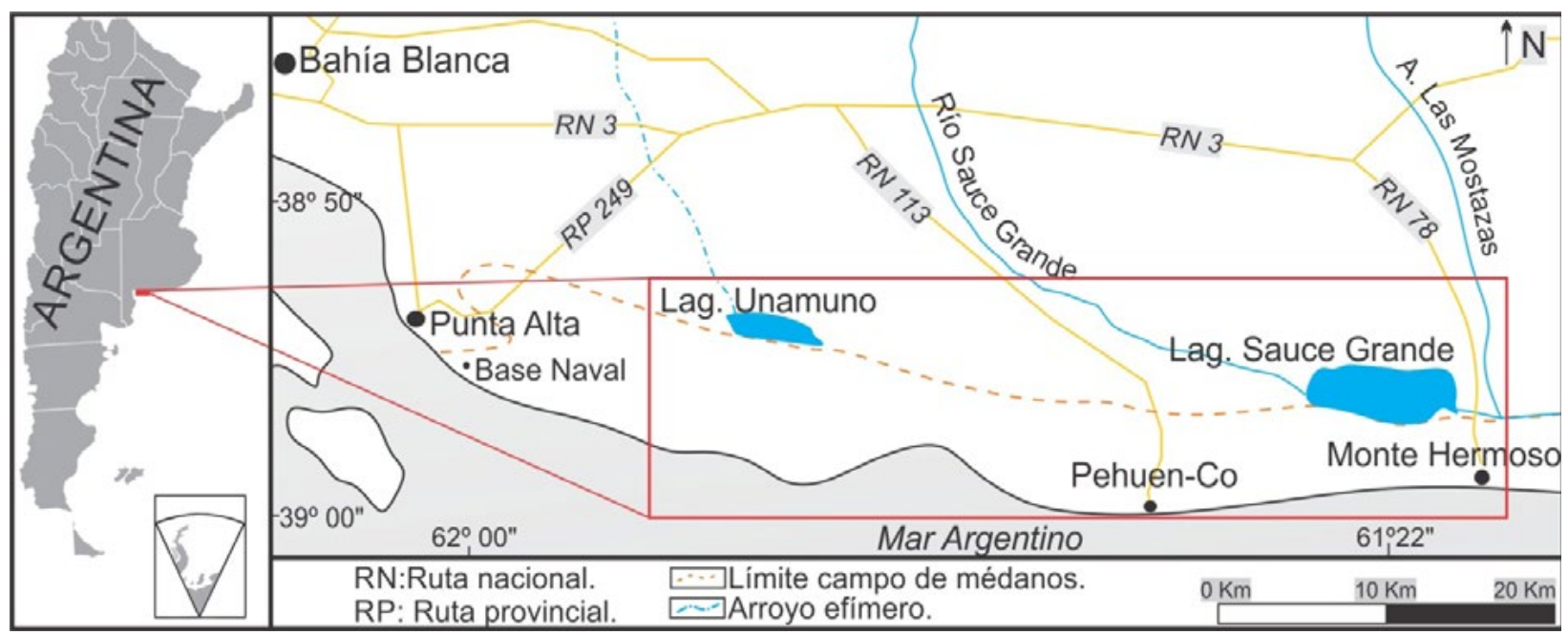

Figura 1. Área de estudio en rectángulo rojo.

Figure 1. The red rectangle marks the study area.

el este del área de estudio) y Unamuno (por el oeste). Se trata de cubetas o depresiones topográficas, con costas bajas, alargadas en sentido oeste-este y noroeste-sureste respectivamente.

\section{Geología e hidrogeología}

En el sector costero del sudoeste bonaerense se destaca como principal geoforma un cordón medanoso de orientación este-oeste. Este cordón, limita al norte con la llanura pampeana y al sur con el mar argentino. En el límite norte (llanura) se generan sectores anegados, relacionados al afloramiento de la capa freática.

Los depósitos existentes se encuentran genéticamente vinculados con las variaciones del nivel del mar ocurridas durante el periodo Neógeno, encontrándose depósitos tanto de origen continental como marino
(Aramayo et al., 2002). La extensa cubierta arenosa limita los afloramientos más antiguos a sectores de acantilados costeros o terrazas fluviales, los cuales han sido objeto de análisis por varios autores (Ameghino 1889, 1898; Fidalgo et al., 1975; Fidalgo y Tonni 1982; Zavala 1993, entre otros). A escasa profundidad se reconocen dos medios acuíferos. El más profundo de ellos corresponde a la Fm. Monte Hermoso (Zavala, 1993), compuesta mayormente por limolitas arcillosas, limolitas arenosas y areniscas finas, correlacionables con los "Sedimentos Pampeanos" (Fidalgo et al., 1975). Dicha formación presenta un comportamiento acuífero/acuitardo, alojando agua dulce a salobre con conductividades eléctricas medias de $2000 \mu \mathrm{S} / \mathrm{cm}$, de calidad química buena a regular, con tenores elevados de $\mathrm{F}$ y As. Hidrodinámicamente se reconoce un flujo de dirección norte-sur, el cual finaliza su trayecto

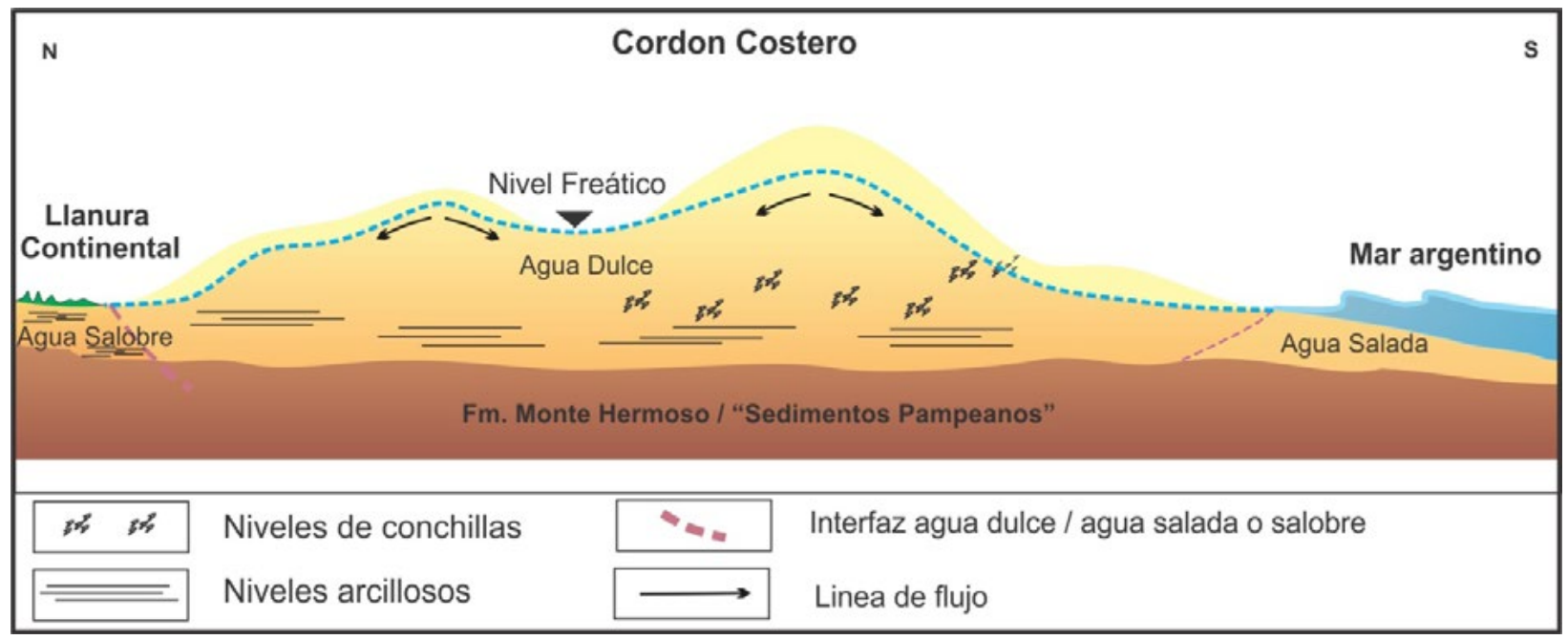

Figura 2. Modelo hidrogeológico del sector costero.

Figure 2. Hydrogeological model of coastal sector 
descargando en el mar. La recarga se produce tanto en la llanura pampeana por excesos hídricos de las precipitaciones como en el cordón costero por conexión hidráulica con el acuífero alojado en el mismo.

Suprayaciendo a lo anterior, se encuentra un acuífero de carácter libre, alojado en sedimentos y rocas psamiticas pertenecientes a las formaciones Puerto Belgrano (Pleistoceno superior), Punta Tejada (Pleistoceno superior-Holoceno medio) (Zavala, 1993) y a los depósitos modernos que forman los médanos costeros. Aloja agua dulce cuya conductividad eléctrica promedio es de $700 \mu \mathrm{S} / \mathrm{cm}$, apta para el consumo humano, configurando la principal fuente de abastecimiento para las localidades balnearias del sector. La recarga depende de los excesos hídricos generados por las precipitaciones. El nivel freático tiende a copiar de manera suave los rasgos topográficos, reconociéndose de manera local domos con flujos radiales divergentes hacia los sectores de inter-duna (Figura 2). De forma más regional, el cordón costero presenta dos flujos diferenciados, uno hacia el sector norte (Ilanura pampeana) y otro hacia el sur (mar). De esta manera se generan dos interfaces, una agua dulce-agua salobre en el sector norte y otra agua dulce-agua salada en el sector sur.

\section{Tipificación y clasificación hidrológica de los humedales}

\section{Laguna Sauce Grande}

La Laguna Sauce grande se presenta como un cuerpo permanente de agua salobre, de escasa profundidad (hasta $2 \mathrm{~m}$ ), ubicada en el partido de Monte Hermoso, a $4 \mathrm{~km}$ al noroeste de la ciudad homónima.

Sus fuentes de llenado la componen el río Sauce Grande, el cual alimenta la laguna desde el sector oeste con un caudal medio de $2,7 \mathrm{~m}^{3} / \mathrm{s}$ (EdiUNS 2005) y la descarga de agua subterránea proveniente de los acuí- feros alojados tanto en los sedimentos pampeanos al norte, como en el cordón de dunas costeras al sur de la laguna. La descarga subterránea se desprende del análisis del mapa freatimétrico del partido de Coronel Dorrego (EdiUNS 2005) y de datos de niveles piezométricos medidos en el cordón de dunas costeras.

El vaciado se produce principalmente a través de una desembocadura existente en su extremo este, donde el río Sauce Grande continúa su camino hasta finalizar kilómetros después, en el mar. Otro factor o término de salida es la evaporación directa del cuerpo de agua y la evapotranspiración generada por la vegetación que dominan sus costas, la cual se infiere a partir de los datos de evapotranspiración potencial calculados para el área.

Al encontrarse en una región árida a semi-árida, la variación de los caudales erogados por el río Sauce Grande depende de la estacionalidad de las precipitaciones y de la descarga de agua subterránea al curso (caudal básico). Estos dos aspectos se encuentran íntimamente relacionados a las series de años secos y húmedos. A su vez las tomas ilegales de agua para riego disminuyen de manera evidente el caudal del río. Esto influye directamente en la laguna, reduciendo su tamaño y desmejorando la calidad química del agua en periodos de sequía extensa (Figura 3). Hidroquímicamente, el cuerpo de agua se presenta como oligohalino con una salinidad de 3,5 g/L y pH 9 (Ferrer et al., 2012).

\section{Humedales en el ambiente de dunas}

Las dunas o médanos costeros son geoformas dinámicas, las cuales deben su origen a las acumulaciones de sedimentos transportados por el viento. Este agente modela la superficie de las mismas, generando sectores tanto de depositación como de erosión. Es así que, entre la cresta y el seno de un médano puede haber una diferencia de altura significativa.

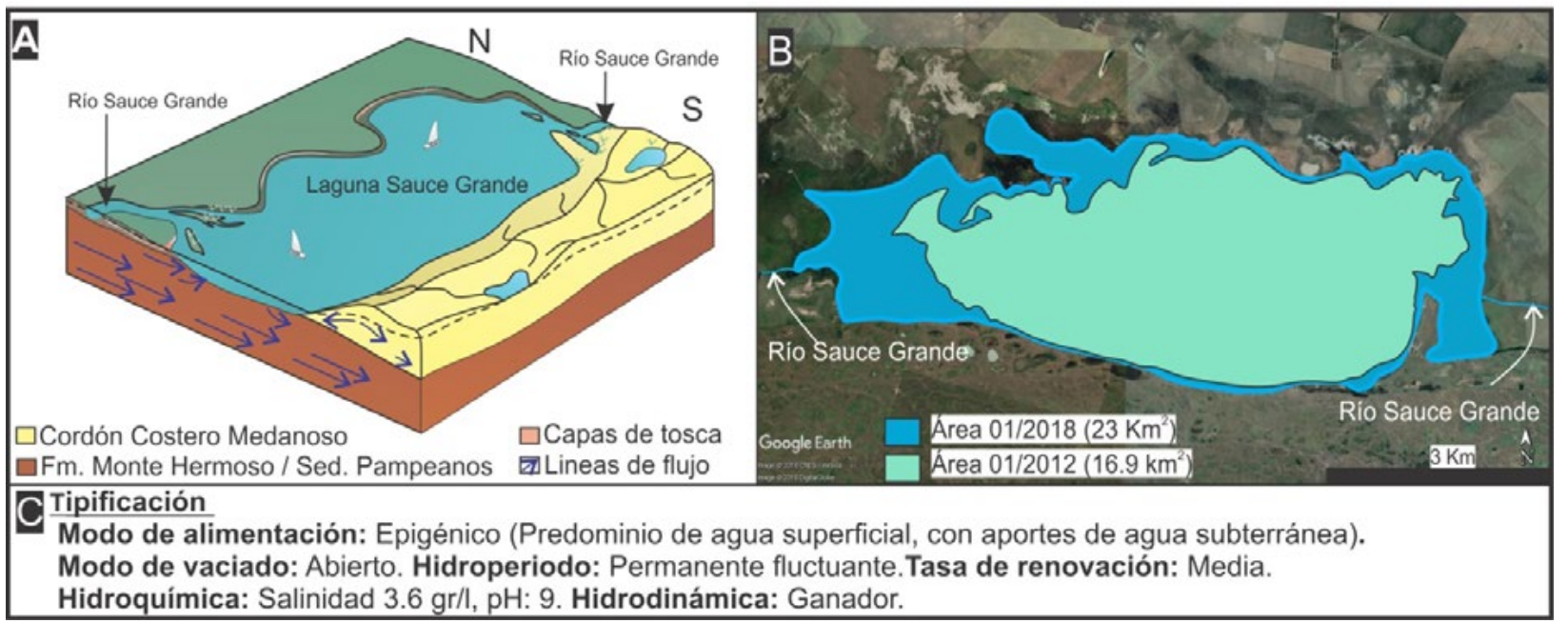

Figura 3. A) Modelo de hidrogeológico de la Laguna Sauce Grande. B) Variaciones areales de la laguna. C)Tipificación hidrológica. Figure 3. A) Hydrogeological model of Sauce Grande lagoon. B) Areal variations in time. C) Hydrological typification. 
El nivel freático del acuífero libre alojado en el cordón costero, copia de forma suave la topografía del mismo. En épocas húmedas, donde la recarga aumenta, suele ocurrir que, en sectores topográficamente bajos entre las crestas de los médanos, el nivel freático iguala o supera al topográfico, generando zonas inundadas $o$ anegadas. Dichos sectores conforman los humedales de inter-duna, también llamados ojos de agua (Figura 4). Las oscilaciones del nivel freático analizadas en sitios de similares características geológicas y geomorfológicas, dentro del cordón de dunas costero, indican que las mismas no suelen superar los $0,77 \mathrm{~m}$ en un régimen pluviométrico de unos 894 $\mathrm{mm} / \mathrm{a}$ (Rodrígues Capítulo et al, 2013).

Como se dijo, la presencia de estos humedales depende de las oscilaciones del nivel freático, aunque algunos se encuentran de manera permanente mientras que otros son temporales y estacionarios. El modo de vaciado es por evaporación directa del cuerpo de agua, evapotranspiración y profundización del nivel freático.

Hidroquímicamente, el agua de estos humedales tiende a contener más sales que el agua del acuífero que los alimenta. Esto sucede debido a la concentra-

\section{Laguna Unamuno}

Ubicada a $18 \mathrm{~km}$ al noroeste de la localidad de Pehuen-Có se encuentra la laguna Unamuno. Se presenta como un cuerpo de agua permanente de poca profundidad (menor a 4 metros) emplazada en el sector limítrofe entre el cordón costero medanoso y la Ilanura pampeana.

Su fuente de alimentación la componen el acuífero freático de la llanura y los aportes estacionales, en períodos húmedos, del acuífero libre en las dunas y del arroyo Napostá chico (Figura 5). Esta laguna constituye el nivel de base del arroyo configurando así el sector inferior de su cuenca, de tipo endorreica. Dicho arroyo alcanza o alimenta a la laguna solo en los periodos húmedos, ya que, durante el resto del año, su caudal es muy bajo y se infiltra en la llanura pampeana antes de arribar al cuerpo de agua. Su influencia es estacional, la cual puede ser considerable. Como otro termino de Ilenado no habría que descartar la descarga de un flujo somero y local desde las dunas hacia la laguna.

Su vaciado se produce por evaporación directa y evapotranspiración. Analizando el mapa piezométrico del sector (Valdez y Silva Busso, 2016) no habría que descar-

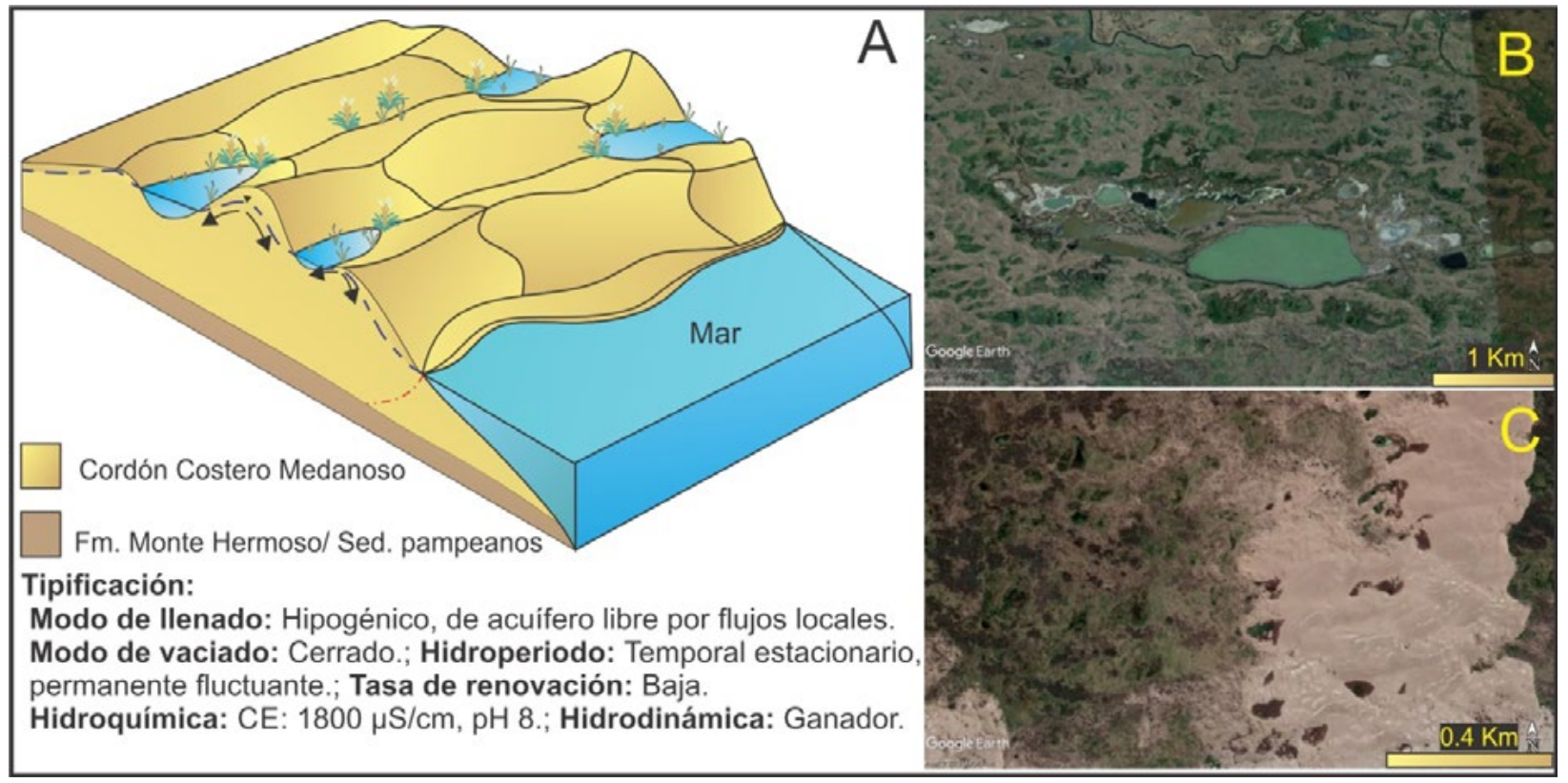

Figura 4. A) Modelo de funcionamiento de los humedales en el ambiente de dunas y tipificación. B) Humedal de inter-duna permanente y fluctuante. C) Humedal de inter-duna temporal y estacionario.

Figure 4. A) Operating model of coastal wetlands in the dune environment and hydrological typification. B) Permanent and fluctuating interdune wetland. C) Temporary and stationary inter-dune wetland.

ción de sales, producto de la evaporación del cuerpo de agua. La conductividad eléctrica registrada en los humedales ronda los $1800 \mu \mathrm{S} / \mathrm{cm}$, mientras que en el acuífero freático promedia los $700 \mu \mathrm{S} / \mathrm{cm}$. Estos valores pueden aumentar durante la estación estival y/o periodos secos. tar transferencia de agua desde la laguna a los médanos y al acuífero pampeano subyacente, durante períodos secos, cuando el nivel freático en las dunas está por debajo del pelo de agua de la laguna (Figura 5).

Si bien la laguna es de carácter permanente, la variación de su superficie de acuerdo al advenimiento 
de años pluviométricamente secos y húmedos es notable. Durante el año 2002, donde la media pluviométrica para el período comprendido entre los años 1999 y 2002 fue de $925 \mathrm{~mm} / \mathrm{a}$, su superficie ocupó unos 15 $\mathrm{km}^{2}$. La superficie de la laguna durante el año 2011 se vio reducida a $1 \mathrm{~km}^{2}$. Esta notable disminución coincide con una serie de años secos (2008-2011), donde las precipitaciones ocurridas presentaron un valor medio de $466 \mathrm{~mm} / \mathrm{a}$ (Figura 5).

El agua de la laguna es salobre, de pobre calidad química, presentando una conductividad eléctrica de $3700 \mu \mathrm{S} / \mathrm{cm}$ y un pH 8. Dichas características desmejoran aún más durante los periodos secos por evaporación y concentración de sales (Bohn et al., 2007).

\section{Discusión y conclusiones}

La importancia de los humedales como sustento de la biodiversidad y proveedor de servicios ecosistémicos resulta un aspecto aceptado y difundido tanto en la comunidad científica como en los medios sociales (Piñar Alvarez, et al. 2017). Sin embargo la relación entre el agua subterránea y superficial en estos ambientes es un tema poco difundido y complejo (Ameli y Creed, 2017).

La investigación sobre los procesos de interacción entre los distintos elementos del balance hídrico, es la base para comprender el funcionamiento de estos sistemas (Custodio, 2010). Gran parte de la dificultad respecto al estudio de esos cuerpos radica en la falta de información de campo o el difícil acceso a las zonas de estudio, transformando la utilización de imágenes satelitales en una herramienta fundamental (Halabisky et al, 2016).

Los humedales en zonas Ilanas suelen depender del agua subterránea, convirtiéndose en áreas de descarga de los acuíferos (Custodio, 2010; Romanelli, et al. 2010). En el área de estudio, la información piezométrica disponible, permite vincular la presencia de los humedales con la hidrodinámica subterránea. Esta conexión hidráulica es una característica común entre el agua superficial de la llanura pampeana y el acuífero freático (Kruse y Zimmermann, 2002). Los humedales de inter-duna están relacionados a los sectores de descarga del flujo local del acuífero. Su vaciamiento depende de las oscilaciones del nivel freático y la evaporación. Las oscilaciones piezométricas documentadas en el sector norte de la cadena de dunas, permiten prever un comportamiento similar, pero de menor magnitud debido a las diferencias en la pluviometría.

Las lagunas Sauce Grande y Unamuno, tienen un modo de llenado epigénico y mixto respectivamente y reciben descarga de agua subterránea. El modo de

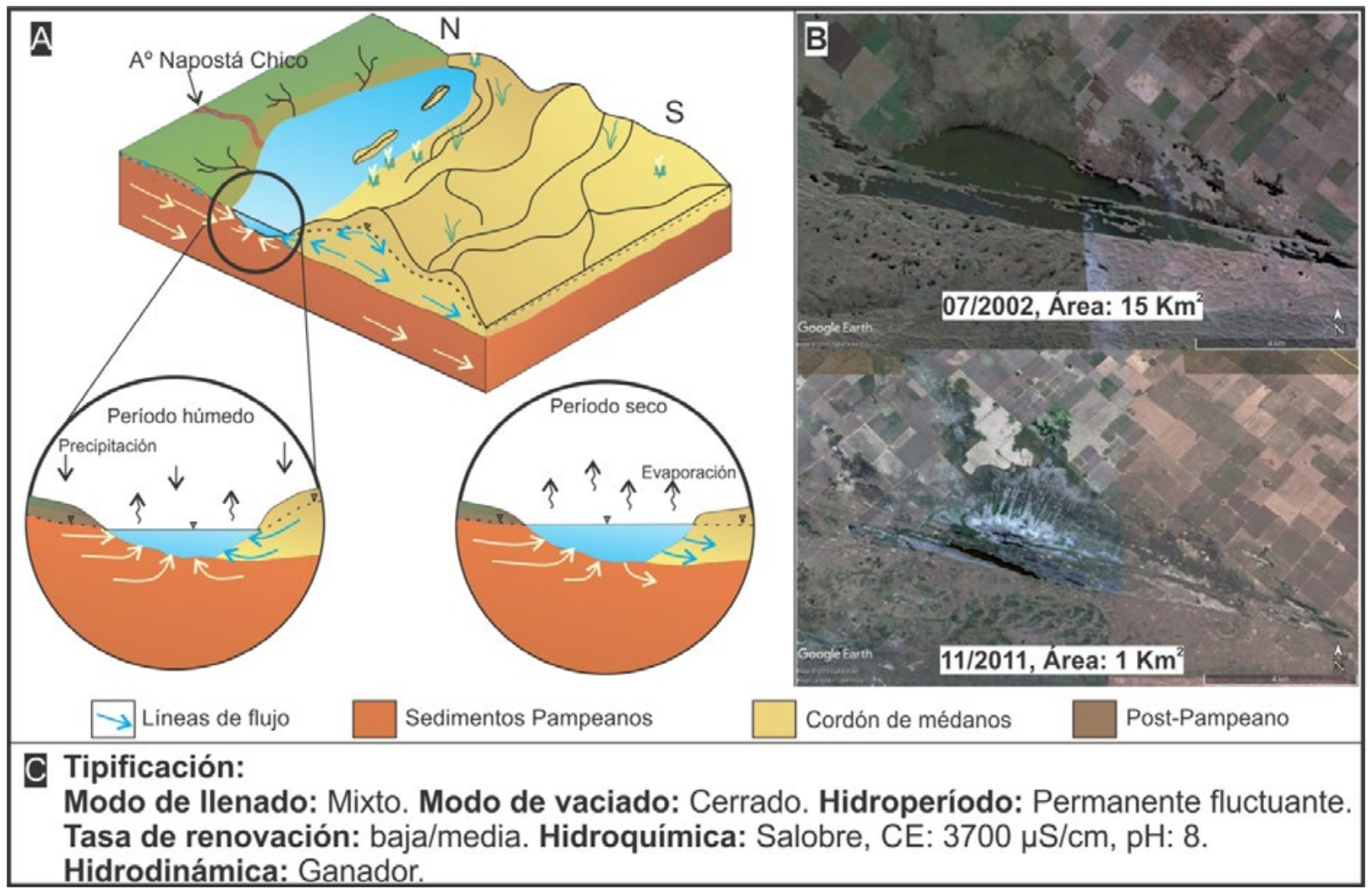

Figura 5. A) Modelo de funcionamiento hidrogeológico de la Laguna Unamuno. B) Variación en la superficie de la laguna. C) Tipificación hidrológica.

Figure 5. A) Hydrogeological functioning model of the Unamuno lagoon. B). Areal variations in time. C) Hydrological typification. 
vaciado de la laguna Unamuno es cerrado, mientras que la Laguna Sauce Grande presenta un egreso de agua superficial constante.

Si bien el estado del conocimiento no permite una formulación cuantitativa de los términos del balance hídrico, el análisis de imágenes satelitales y los registros pluviométricos ponen de manifiesto una relación directa entre las precipitaciones y la variación del almacenamiento superficial del agua, coincidente con lo observado por Bohn et al 2007. Desde un punto de vista químico, los datos de salinidad y conductividad eléctrica solo revelan que las aguas de los humedales están más mineralizadas que la subterránea, entre 2 y 5 veces para los cuerpos lagunares y 2,5 veces para los humedales de interduna. Este incremento se relacionaría al aporte de sales del agua de llenado y a su concentración por evaporación, consistente con las características áridas-semiáridas de la zona de estudio, la cual presenta un recurrente déficit hídrico.

En este aporte se presentan los modelos de funcionamiento hidrológico dominantes en estos cuerpos de agua. En este sentido, esta contribución, constituye el punto de partida para elaborar planes de gestión del recurso hídrico subterráneo, teniendo en cuenta las necesidades antrópicas y sin perder de vista la conservación y el valor de los servicios ecosistémicos de estos humedales.

\section{Referencias}

Ameghino, F., 1889. Contribución al conocimiento de los mamíferos fósiles de la República Argentina. Actas de la Academia Nacional de Ciencias de Córdoba, 6: 1-1027.

Ameghino, F., 1898. Synopsis geológico-paleontológica. Segundo Censo Nacional, Tomo I: 113-225.

Ameli, A. A. y Creed, I. F., 2017. Quantifying hydrologic connectivity of wetlands to surface water systems. Hydrology and Earth System Sciences 21: 1791-808.

Aramayo, S.A., Schillizi, R.A. y Gutiérrez Téllez, B.M., 2002. Evolución paleoambiental del Cuaternario en la Costa Atlántica del sur de la provincia de Buenos Aires, Argentina. Revista de la Sociedad Geológica de España, 15 (1-2): 95-104.

Auge, M., 2004. Regiones Hidrogeológicas, República Argentina y provincias de Buenos Aires, Mendoza y Santa Fe. Universidad de Buenos Aires. 104 pp.

Blanco, L., R. Bo, P. Kandus, G. Lingua, P. Minotti y R. Quintana (editores), 2017. Regiones de humedales de la Argentina. Ministerio de Ambiente y DesarroIlo Sustentable. Fundación Humedales/Wetlands International. Universidad Nacional de San Martín y Universidad Nacional de Buenos Aires. 337 pp.

Bohn, V., Piccolo, M., Perillo, G., 2007. Potencial uso agrícola del agua de la laguna Unamuno. Buenos Aires, Argentina. Asociación Española de Ecología Terrestre, Ecosistemas 16 (2): 77-85.

Custodio, E., 2010. Las aguas subterráneas como elemento básico de la existencia de numerosos hu- medales. Ingeniería del Agua, 17(2): 119-135.

Di Martino, C., Albouy, R., Marcos, A. y Carrica. J., 2016. Gestión del agua subterránea en los médanos costeros de Monte Hermoso, Argentina. IX Congreso Argentino de Hidrogeología. EBook: Gobernanza del agua en áreas con escasez: gestión de las aguas subterráneas: 62-67.

EdiUNS, 2005. Geoambiente y evaluación de las aguas freáticas del Partido de Coronel Dorrego (Provincia de Buenos Aires). Juan Darío Paoloni y Magdalena González Uriarte Editores. Editorial de la Universidad Nacional del Sur. Buenos Aires, 108 pp.

Ferrer, N.C, Cony, N.L, Fornerón, C.F. y Piccolo, M.C., 2012. Caracterización del fitoplancton y estado tròfico de la laguna Sauce Grande (Provincia de Buenos Aires, Argentina) en el otoño de 2010. Biología Acuática $\mathrm{N}^{\circ}$ 27. 129-141.

Fidalgo, F., De Francesco, F. O. y Pascual, R., 1975. Geología superficial de la llanura bonaerense. Relatorio del VI Congreso Geológico Argentino. Bahía Blanca. 103-108.

Fidalgo, F. y Tonni, E. P., 1982. Observaciones geológicas y paleontológicas en las "Barrancas de Monte Hermoso" (Provincia de Buenos Aires). III Congreso Argentino de Paleontología y Bioestratigrafía. Corrientes. Resúmenes: 16-17

González, N., 2005. Los ambientes hidrogeológicos de la provincia de Buenos Aires. Geología y Recursos Minerales de la provincia de Buenos Aires. XVI Congreso Geológico Argentino, Relatorio: 359-374.

Halabisky, M., Moskala, L. M., Gillespie, A. Hannam, M., 2016. Reconstructing semi-arid wetland surface water dynamics through spectral mixture analysis of a time series of Landsat satellite images (1984-2011). Remote Sensing of Environment, Volumen 177: 171-183.

Instituto Nacional de Estadística y Censos INDEC., 2010. Censo Nacional de Población, Hogares y Viviendas, 25/10/2018, https://www.indec.gob.ar.

Kruse, E. y Zimmermann, E., 2002. Hidrogeología de Grandes Llanuras. Particularidades en la Llanura Pampeana (Argentina). Workshop. Groundwater and Human Development. XXXII IAH Congress. Mar del Plata, Argentina.

Manzano, M., 2015. El papel del agua subterránea en los servicios ecosistémicos de los humedales que contribuyen al bienestar humano. En: Segundas Jornadas. El papel de agua subterránea en el funcionamiento de los humedales. Resumenes de las ponencias. Girona, España.

Manzano, M., F. Borja y C. Montes., 2002. Metodología de tipificación hidrológica de los humedales españoles con vistas a su valoración funcional y a su gestión. Aplicación a los humedales de Doñana. Boletín Geológico y Minero, 113 (3): 313-330.

Piñar Alvarez, M., A., Wojtarowski Leal. A., Martínez-Vázquez. M., L., 2017. Dunas costeras en Veracruz, México: Conservación y uso para la cohesión social desde la percepción local. Regions and Cohesion, Volumen 7, Issue 1, 40-68. 
Rodrígues Capítulo, L., Kruse, E. y De Bernardi, P., 2013. Fluctuaciones de niveles hidráulicos en un sector costero de la provincia de Buenos Aires, caso de estudio Pinamar. En:Temas actuales de la hidrología subterránea. Editorial de la Universidad Nacional de la Plata, $421 \mathrm{p}$.

Romanelli, A., Quiroz Londoño, O. M., Massone, H. E., Martinez, D. E. y Bocanegra, E. 2010. El agua subterránea en el funcionamiento hidrológico de los humedales del Sudeste Bonaerense, Buenos Aires, Argentina. Boletín Geológico y Minero de España, 121 (4): 373-386

Servicio Meteorológico Nacional. Estación Bahía Blanca. 05/07/2018, https://www.smn.gob.ar.

Thornthwaite, C., W., 1948. An approach toward a ra- tional classification of climate. Geologic. Rev. Vol. 38: 55-94.

Valdés, S. y Silva Busso, A., 2016. Aspectos hidrogeológicos de la zona costera entre Pehuén-Có y Punta Alta, provincia de Buenos Aires. IX Congreso Argentino de Hidrogeología y VII Seminario Hispano-Latinoamericano Sobre Temas Actuales de la Hidrología Subterránea. Catamarca, Argentina. Relatorio: 79-86.

Zavala, C., 1993. Estratigrafía de la localidad de la Farola de Monte Hermoso (Plioceno - Reciente). Provincia de Buenos Aires. XII Congreso Geológico Argentino y II Congreso de Exploración de Hidrocarburos Actas Tomo II: 228 - 235.

Recibido: julio 2019

Revisado: noviembre 2019

Aceptado: enero 2020

Publicado: marzo 2021 